\title{
A INFÂNCIA SEM TERRA EM MOVIMENTO NA LUTA POR ESCOLA, TERRA E DIGNIDADE ${ }^{1}$
}

\author{
Lia Pinheiro Barbosa \\ Mirna Sousa Sales
}

RESUMO: Na consolidação do projeto educativo-político do Movimento dos Trabalhadores Rurais Sem Terra (MST), a Infância Sem Terra torna-se um dos pilares da subjetividade política das crianças acampadas e assentadas, resultado de um processo permanente de debate político, estudo e aprofundamento teórico sobre o significado da infância Sem Terra articulada à práxis política do MST. No presente escrito nos interessa apresentar alguns elementos reflexivos do processo de consolidação da Infância Sem Terra na organicidade do MST e o papel desempenhado pelos Sem Terrinba na histórica luta por escola, terra e dignidade que perpassa a resistência camponesa não só no Brasil, mas em toda América Latina. Organizamos o escrito em quatro seções: na primeira, apresentamos a essência do projeto educativo do MST na ruptura das cercas do latifúndio do saber e do conhecimento. Em seguida, adentramos à abordagem da Infância Sem Terra e a educação das crianças Sem Terrinha. Na terceira seção, apresentamos a experiência educativo-pedagógica das Cirandas Infantis e seu papel na subjetividade política dos Sem Terrinha. Finalizamos nossa reflexão destacando os avanços, os desafios e as bandeiras de

1 O presente artigo é resultado da pesquisa realizada durante a Especialização em Desenvolvimento Sustentável e Educação do Campo - Residência Agrária, realizada na Universidade Federal do Ceará (UFC) campus Cariri.

2 Socióloga e doutora em Estudos Latino-Americanos. Docente no Programa de PósGraduação em Sociologia (PPGS), no Mestrado Acadêmico Intercampi em Educação e Ensino (MAIE) e na Faculdade de Educação de Crateús (FAEC) da Universidade Estadual do Ceará (UECE) - Grupo de Pesquisa Pensamento Social e Epistemologias do Conhecimento na América Latina e Caribe. Linha de Pesquisa 1: Mobilizações Sociais, Campo e Cidade. Linha de Pesquisa 2: Trabalho, Educação e Movimentos Sociais. E-mail: lia.barbosa@uece.br.

${ }^{3}$ Pedagoga e Especialista em Desenvolvimento Sustentável e Educação do Campo - Residência Agrária. Pedagoga na Cáritas Diocesana - Ceará. E-mail: mirnamix@hotmail.com. 
luta que impulsam a práxis política dos Sem Terrinha na perspectiva da Infância Sem Terra no movimento da práxis educativo-política do MST. Realizamos pesquisa documental, com a análise de documentos produzidos pelo Setor de Educação do MST e que estruturam a concepção da Infância Sem Terra e as diretrizes filosóficas e pedagógicas de sua proposta educativa. Também realizamos pesquisa de campo em áreas de assentamento na microrregião dos Sertões de Crateús, Ceará.

PALAVRAS-CHAVE: Infância; Sem Terrinha; Ciranda Infantil; MST.

\title{
THE LANDLESS CHILDHOOD IN THE STRUGGLE OF THE MST FOR SCHOOL, LAND AND DIGNITY
}

\begin{abstract}
In the consolidation of the educational-political project of the Landless Rural Workers Movement (MST), the "Landless Childhood" has become one of the pillars of political subjectivity of encamped and settled children, resulting from a permanent process of political debate, study and theoretical deepening of the meaning of landless childhood as part the political praxis of the MST. In the present paper we present some reflections of the process of consolidation of the Landless Childhood in the MST and the role played by landless children ("Sem Terrinha") in the historic struggle for school, land and dignity that permeates peasant resistance not only in Brazil, but in all of Latin America. We have organized the paper in four sections: first, we present the essence of the MST's educational project in breaking down the enclosure of knowledge. Then we examine the Landless Childhood approach and the education of the landless children. In the third section, we present the educational-pedagogical experience of day-care centers and their role in the political subjectivity of the landless children. We conclude our reflection by highlighting the advances, the challenges and the banners of struggle that drive the political praxis of the Landless in the perspective of the Landless Childhood, as part of the educational-political praxis of the MST. The article is a documentary research result, with the analysis of documents produced by the MST Education Sector and which structure the conception of Landless Childhood and the philosophical and pedagogical guidelines of its educational proposal. We also conducted field research in settlement areas in the Sertões de Crateús, Ceará micro-region.
\end{abstract}

KEYWORDS: Childhood; Landless; Day Care; MST. 


\section{INTRODUÇÃO}

O Movimento dos(as) Trabalhadores(as) Rurais Sem Terra (MST) tem construído uma nova concepção de educação, ligada à história da luta pela terra e a um projeto político de desenvolvimento cultural e econômico do, no e para o campo. Nessa trajetória de mais de três décadas, o MST tem se dedicado a consolidar linhas pedagógicas e políticas para impulsionar processos educativos no contexto dos acampamentos e assentamentos, na defesa do direito à educação para crianças, jovens e adultos do campo (MST, 1998; 2000; 2005; 2008a; 2008b; 2011; 2017). Essas bandeiras estão relacionadas com o direito à educação desde o nível básico até o superior, a adoção de uma pedagogia própria, uma metodologia e práticas educativas que fortaleçam o vínculo identitário com o campo e com a luta política do MST, entre acampados e assentados.

$\mathrm{Na}$ assunção de uma dimensão política do ato educativo, a educação sob a ótica do MST deve assumir por princípios filosóficos e políticos a transformação social, a crítica à estrutura de classe da sociedade do capital e a construção da nova mulher e do novo homem, reconstruídos na superação das relações de opressão e desumanização (FREIRE, 1987), em que se projetam "transformações na forma de ser das pessoas e da sociedade, cultivando valores radicalmente humanistas, que se contrapõem a valores anti-humanos que sustentam a sociedade capitalista atual" (MST, 1999, p. 25). A luta pela democratização do acesso ao conhecimento, de forma orgânica com a luta do Movimento, é uma das estratégias na disputa de projetos educativos no campo. O percurso de construção do projeto educativo-político do MST iniciou-se desde as primeiras ocupações de terras improdutivas, instigado pela necessidade de educar os filhos e filhas da classe trabalhadora do campo na perspectiva da luta de classes, da conformação de uma identidade política Sem Terra.

Assim, o MST realizou, em 1987, o I Encontro Nacional de Educação em Assentamentos com o intuito de discutir internamente a proposta educativa do Movimento. Nesta ocasião, foi criado o Setor de Educação do MST, fundado com o objetivo de organizar e articular uma proposta pedagógica específica para as experiências educativas dos 
acampamentos e assentamentos. Assim, desde a sua fundação este Setor assumiu o compromisso de elaborar uma proposta educativo-pedagógica que contemple todas as especificidades da realidade do campo e do Movimento.

A presença de crianças nos primeiros acampamentos e, logo, nos assentamentos da Reforma Agrária abriu um debate fundamental no cerne do MST: Como lidar com a presença das crianças no âmbito dos acampamentos? Na consolidação da nova mulher e do novo homem, qual o lugar social e político ocupado pelas crianças? Como incorporá-las ao processo de luta pela terra e pela plena realização da Reforma Agrária?

$\mathrm{Na}$ dialética da resistência do MST, as perguntas sobre as crianças colocaram em movimento o primordial debate sobre a Infância e, em particular, sobre o que posteriormente se denominou como a Infância Sem Terra. Na compreensão crítica de que a luta pela terra prescinde o sujeito histórico-político Sem Terra e que este, por sua vez, corresponde às famílias camponesas, que incorpora seus filhos, o MST reflete (MST, 2011, p. 25):

\begin{abstract}
Precisamos entender que as crianças têm iniciativas, têm opiniões, e que, muitas vezes, ao questionarem os adultos em suas atitudes, impulsionam mudanças. Se observarmos atentamente e dermos espaço é possível vermos na autoorganização das crianças em suas atividades e na relação com os adultos a criação e a produção de coisas novas e autênticas.
\end{abstract}

Hoje, na consolidação do projeto educativo-político do MST, a Infância Sem Terra se consolida como um dos pilares da subjetividade política dos Sem Terra, resultado de um processo permanente de debate político, estudo e aprofundamento teórico sobre o significado da infância articulada à práxis política do MST.

No presente escrito nos interessa apresentar alguns elementos reflexivos do processo de consolidação da Infância Sem Terra na organicidade do MST e o papel desempenhado pelos Sem Terrinha na histórica luta por escola, terra e dignidade que perpassa a resistência 
camponesa não só no Brasil, mas em toda América Latina. Os dados apresentados são resultados de pesquisa histórico-documental, em que analisamos os documentos elaborados pelo Setor de Educação do MST e que estruturam as diretrizes filosóficas e pedagógicas de sua proposta educativa, bem como sua concepção de Infância Sem Terra. Também realizamos pesquisa de campo em áreas de assentamento no Ceará, em particular na microrregião dos Sertões de Crateús, ${ }^{4}$ com a realização de entrevistas junto a membros do Setor de Educação e observações das experiências educativas junto à Infância Sem Terra ${ }^{5}$.

Organizamos o escrito em quatro seções: na primeira, apresentamos a essência do projeto educativo do MST na ruptura das cercas do latifúndio do saber e do conhecimento. Logo, adentramos à abordagem da Infância Sem Terra e a educação das crianças Sem Terrinha. Na terceira seção, apresentamos a experiência educativo-pedagógica das Cirandas Infantis e seu papel na subjetividade política dos Sem Terrinha. Finalizamos nossa reflexão destacando os avanços, os desafios e as bandeiras de luta que impulsam a práxis política dos Sem Terrinha na perspectiva da Infância Sem Terra.

\section{A ROMPER AS CERCAS DO LATIFÚNDIO DO SABER E DO CONHECIMENTO: O PROJETO EDUCATIVO DO MST}

Nascido na clandestinidade dos anos de "chumbo" da ditadura militar, ao final dos anos 1970 do século XX, o MST tornou-se um dos mais emblemáticos movimentos sociais do campo do Brasil e da América

${ }^{4}$ A microrregião dos Sertões de Crateús está composta por cinco municípios, a saber: Crateús, Nova Russas, Novo Oriente, Independência, Tamboril.

5 Importante destacar que o MST - Ceará impulsionou os primeiros debates e experiências em torno da Infância Sem Terra e a educação dos Sem Terrinha. Esclarecemos que em nossa pesquisa não entrevistamos diretamente as crianças (embora destacamos, ao longo do texto, o posicionamento dos Sem Terrinha, extraídos de documentos de trabalho e de sistematização do MST), dado que nosso objetivo geral consistia em debater a Infância Sem Terra no âmbito da luta pela terra, pela realização da Reforma Agrária e na defesa do direito à educação nas escolas de acampamentos e assentamentos. Por tal razão, o enfoque da pesquisa é históricodocumental e com a delimitação do Setor de Educação como interlocutor na pesquisa. Pretendemos dar continuidade à pesquisa com a inserção direta da voz das crianças Sem Terra. 
Latina. Herdeiro da memória histórica das lutas empreendidas no campo brasileiro, sua gênese está intimamente relacionada com a denúncia histórica do significado cultural, econômico e político do latifúndio nas relações sociais e produtivas no campo e na cidade.

Com a abertura democrática em meados dos anos 80, o MST assume sua identidade de movimento social do campo, com a realização do Primeiro Encontro Nacional de Trabalhadores Rurais Sem Terra, em 1984, em Cascavel - PR. O encontro tinha por finalidade convocar e articular os trabalhadores rurais da região a uma resposta política à histórica problemática agrária, por meio da luta pela desapropriação das terras improdutivas e sua apropriação pelas famílias camponesas.

O debate político anunciado nesse primeiro encontro nacional constituiu um marco na gênese do projeto político do MST. Neste sentido, o encontro objetivou organizar a luta conjunta em defesa da conquista da terra, na discussão coletiva de um projeto político-econômico para o campo brasileiro, pautado na defesa da Reforma Agrária. Assim, nasce, oficialmente, o Movimento dos Trabalhadores e Trabalhadoras Rurais Sem Terra - MST.

O primeiro locus e símbolo da resistência Sem Terra são as ocupações e os acampamentos, uma forma genuína da luta camponesa, uma vez que transforma a ocupação em um fato político, que conduz a uma pressão à negociação da expropriação das terras improdutivas e para a realização da Reforma Agrária (BARBOSA, 2013a). Desde o início, o MST compreendeu que a Reforma Agrária como projeto político popular prescindia a formação do sujeito histórico-político para a sua consolidação. Daí emerge o debate interno relacionado à centralidade da formação política e educativa das famílias camponesas no âmbito dos acampamentos e, em particular, da militância Sem Terra, para fortalecer a dimensão identitária e política de permanência no campo.

Nesse contexto, o MST considera fundamental retomar a reflexão em torno à educação no processo formativo do sujeito histórico-político Sem Terra, uma reflexão inspirada no legado da Pedagogia Socialista, da Educação Popular, do pensamento pedagógico latino-americano, notadamente aquele de base freiriana, no sentido de ruptura das relações 
de opressão no âmbito da consciência e de construção de uma educação libertadora. A educação no marco da luta pela terra e pela realização da Reforma Agrária pressupõe a assunção da consciência de classe, isto é, de classe trabalhadora do campo.

Por outro lado, uma educação libertadora no âmbito da luta pela Reforma Agrária se assenta na compreensão de que a ruptura do latifúndio da terra requer, a priori, a ruptura do latifúndio do saber e do conbecimento (STÉDILE, 1997) ${ }^{6}$. Nesta perspectiva, a luta pelo direito à educação é reconhecida como necessidade histórica, fundamental como elemento estratégico para a construção de um projeto popular. Com base no exposto, a educação é apreendida pelo MST como um instrumento moral e intelectual indispensável à luta política da classe trabalhadora do campo na construção do socialismo.

Daí que uma das prioridades do Movimento consistiu na articulação política na defesa e garantia do acesso à educação, o que evidencia a preocupação com a formação educativo-política de sua militância. Assim, no decorrer de sua trajetória política, o MST construiu uma proposta educativo-pedagógica que não se reduziu a um modelo tradicional, de mera transferência de conhecimentos acumulados, de caráter escolarizado. Ao contrário, a luta pelo direito à educação e à escola começou com a disputa teórico-epistêmica do conceito de educação, pedagogia e escola na perspectiva da práxis política do MST (BARBOSA, 2015b).

Por tal razão, o MST construiu uma pedagogia genuína, a Pedagogia do Movimento (CALDART, 2004) que vincula o processo educativo com a cotidianidade da luta pela terra e pela Reforma Agrária. Uma concepção de educação que fomenta uma geopedagogia do conhecimento ${ }^{7}$ (BARBOSA,

\footnotetext{
${ }^{6}$ O MST reiteradas vezes afirma, no âmbito do seu discurso político e de alguns documentos, de que é necessário romper todas as cercas, entre elas, aquelas que o Movimento define como as cercas do latifúndio do saber e do conhecimento, que expressam a negação histórica do direito à educação, da Educação Básica à Educação Superior, para os povos do campo. Grifos das autoras para salientar essa denúncia do MST.

${ }^{7}$ A geopedagogia do conhecimento constitui a relação que se estabelece entre a pedagogia e os elementos socioculturais que emergem do território e da cultura. Para pensar esta dimensão da pedagogia, recuperamos as análises de Milton Santos (2000) sobre a espacialidade social como construção socio-histórica. Com base nesta perspectiva, se compreende o lugar de
} 
2013b; 2015b), em que se confere um sentido pedagógico à sua luta social, fazendo dela momento de formação educativa e política não só da militância de base, mas do conjunto dos sujeitos partícipes do processo.

As experiências educativas do MST são desenvolvidas com base nos princípios filosóficos e pedagógicos do Movimento. Os princípios filosóficos dizem respeito à visão de mundo defendida pelo MST e direcionados ao ideário de transformação social. Para tanto, se vincula a educação ao trabalho como princípio educativo, com o intuito de fortalecer os princípios de cooperação, bem como fomentar o conhecimento do ser humano em suas múltiplas dimensões. Neste sentido, a educação é compreendida como um processo permanente de formação (MST, 2005).

Os princípios pedagógicos referem-se ao jeito de pensar e pôr em prática os princípios filosóficos da educação do MST, ou seja, é a reflexão metodológica dos processos educativos. Atentam para a combinação teoriaprática, com o entrelaçar do processo de ensino e capacitação; utilizam a realidade de vida e de luta como base construtiva de conhecimento. Há um liame entre a pesquisa e os processos educativos, políticos, econômicos e culturais (MST, 2005).

A escola igualmente é elemento de análise no marco de construção de uma proposta de educação em consonância com a práxis política do MST. Para o Movimento, a escola tem uma função social e política na sociedade, uma vez que serve como espaço de reprodução das estruturas de poder próprias do capital. Conforme o MST (1987), "a classe dominante usa a escola como um dos principais meios de controle ideológico para manter a ordem atual e sustentar o sistema capitalista" 8 .

Tal crítica toma por base o reconhecimento de que o modelo de escola preconizado pelo capitalismo reproduz e reforça sua própria ideologia. Um modelo educativo que estabelece uma dominação pelo

inscrição do pedagógico como uma geopedagogia que nos permite discutir de que maneira os movimentos sociais consolidam uma práxis educativo-política baseada no conjunto de saberes e na multiplicidade de elementos constitutivos da experiência política, as quais possuem raízes próprias de seus territórios e culturas (BARBOSA, 2014; 2015).

${ }^{8}$ Documento do $1^{\circ}$ Seminário Nacional de Educação em Assentamentos. São Mateus / ES. 27 a 30 de julho de 1987. 
"saber", ou seja, pelo acesso a um tipo de conhecimento que ensina, desde muito cedo, a assumir a condição subalterna no plano ideológico e econômico? .

Por conseguinte, o MST defende um novo modelo de escola e uma pedagogia que contribuam para uma formação voltada à construção de uma consciência crítica para os povos do campo. Em suma, o caráter educativo do Movimento possui particularidades e especificidades relacionadas à formação e mobilização da sua militância, em permanente disputa com a formação ideológica estabelecida na escola oficial.

A necessidade histórica de ruptura com o latifúndio do saber e do conhecimento conduziu à criação dos Setores de Educação e Formação, ambos destinados à organização de um projeto educativo-político de formação da militância Sem Terra. As primeiras experiências educativas aconteceram nos acampamentos do MST e foram alicerçadas por duas questões centrais: a preocupação com o grande número de analfabetos nos acampamentos e assentamentos, e a presença das crianças. Daí surge duas novas frentes de trabalho, a saber: a Alfabetização de Jovens e Adultos e as chamadas Escolas Itinerantes, pensadas inicialmente para atender a demanda educativa das crianças acampadas e, dessa maneira, assegurar a permanência das famílias nos acampamentos (MST, 2008).

Por ser um movimento de famílias camponesas, o MST sabia da importância de gerar um espaço educativo para as crianças nos acampamentos. Portanto, a Escola Itinerante cumpria um duplo papel político: assegurar a permanência das famílias com crianças e adolescentes em idade escolar no acampamento, dado que muitas famílias, no momento da ocupação, argumentavam que seus filhos e filhas necessitavam regularizar sua situação escolar; e garantir a escolarização de crianças e adolescentes a partir de uma nova concepção de educação e de escola, onde se inicia o processo de formação educativo-política em estreita relação com a resistência e a luta pela terra.

\footnotetext{
${ }^{9}$ Uma reflexão que nos aproxima da análise realizada por Saviani (1983), ao afirmar que o modelo de educação capitalista está dirigido à reprodução de sua própria ideologia. Para o autor, a escola pública brasileira é utilizada como locus de opressão, ao inculcar em todos os níveis educativos o status quo imposto pela classe burguesa e pelo Estado.
} 
A 30 anos de criação do Setor de Educação, o MST avançou nas linhas básicas de seu projeto educativo, incorporando o debate em torno das experiências educativas em acampamentos e assentamentos, na proposta da Educação de Jovens e Adultos, com enfoque na alfabetização e, sobretudo, erigiu a concepção teórico-epistêmica e política da Educação do Campo, que culminou na democratização do acesso à Educação Superior para militantes de organizações e movimentos sociais do campo (BARBOSA, 2013a; 2015a).

$\mathrm{Na}$ atualidade, o MST consolidou suas escolas de formação educativa e política em dois planos: aquelas de caráter autônomo, como a Escola Nacional Florestan Fernandes (ENFF), o Instituto de Educação Josué de Castro, o Centro de Formação Frei Humberto, a Escola Popular de Agroecologia e Agrofloresta Egídio Bruneto, para citar algumas. Outras escolas estão situadas na disputa da Política Nacional de Educação, com a construção e/ou regularização das escolas públicas de Educação Básica no marco da Educação do Campo (BARBOSA, 2016).

Dessa maneira, o MST avançou no atendimento das demandas relacionadas à educação formal, com a conquista do Programa Nacional de Educação para a Reforma Agrária (PRONERA) e da Política Nacional de Educação do Campo. Cabe ressaltar que, embora o projeto educativopolítico do MST tenha iniciado nos anos 80, constitui um projeto em construção, uma vez que dia a dia é vivenciado e recriado nos espaços educativos do MST.

Nesse percurso de formação da nova mulhere do novo homem, a Infância Sem Terra emerge como um sujeito histórico-político fundamental para a continuidade da luta, para o legado geracional do projeto político da Reforma Agrária Popular. Na infância Sem Terra, paulatinamente se constrói a identidade Sem Terrinha, com um posicionamento político fruto do processo educativo e formativo do MST. Vejamos como se deu a incorporação dos Sem Terrinha na práxis educativo-política do MST. 


\section{A INFÂNCIA SEM TERRA E A EDUCAÇÃO DOS SEM TERRINHA}

Conforme mencionamos anteriormente, o Setor de Educação constituiu um dos primeiros setores criados pelo MST com a responsabilidade de pensar e articular as primeiras experiências educativas, tarefa que demandou a gradativa construção da base teórica e metodológica do projeto educativo-político do Movimento. Entre os anos de 1987 a 1994, o Setor de Educação avançou significativamente em sua organicidade, bem como no amadurecimento teórico-político e no delineamento pedagógico da proposta educativa do MST. Durante este período, o Setor de Educação articulou o $1^{\circ}$ Seminário Nacional de Educação em Assentamentos, em 1987, um marco para a elaboração dos primeiros documentos relacionados ao embrião da concepção de Educação para o MST, bem como as linhas básicas da sua proposta educativa no âmbito da alfabetização na EJA e na formação das educadoras e educadores da Reforma Agrária.

Entre os documentos elaborados no decorrer desse período, destacam-se: 1 . Documento do $1^{\circ}$ Seminário Nacional em Assentamentos (1987); 2. Linhas Básicas da Proposta de Educação do MST para as Escolas de Acampamentos e Assentamentos (1990); 3. Proposta Pedagógica do Movimento Sem Terra para as Escolas de Assentamentos e Acampamentos (1991); 4.Educação no Documento Básico do MST (1991) e 4. Uma proposta de Alfabetização de Jovens e Adultos (1994).

Embora desde a gênese do MST e do Setor de Educação se enfatizara a presença das crianças nos acampamentos e assentamentos como elemento impulsor das primeiras experiências educativas, somente no marco do $1^{\circ}$ Congresso Infantil do MST, em 1994, com o tema "A criança e seu espaço na sociedade", que a Infância Sem Terra é incorporada de forma mais sistematizada ao debate educativo-político do Movimento.

Realizado no Rio Grande do Sul, o Congresso foi um marco da mobilização infanto-juvenil organizada pelo Setor de Educação, expandindo-se posteriormente para outros estados do país. Em julho de 1996, em São Paulo, aconteceu a primeira discussão acerca de uma proposta de Educação Infantil no Coletivo Nacional de Educação do MST, uma reflexão que nasceu à raiz da formatura da $5^{\text {a }}$ Turma de Magistério 
da Terra. ${ }^{10}$ Um dos Trabalhos de Conclusão de Curso (TCC) da turma de Magistério da Terra abordou a experiência da Educação Infantil vivenciada pelas crianças do Assentamento $1^{\circ}$ de Abril, no município de Prado - BA. O trabalho titulado Reforma Agrária uma Luta de Todos: dos pequenos também fortaleceu a discussão sobre a Educação Infantil no Setor de Educação. Em consequência desse debate se constitui a Frente de Educação Infantil Nacional, que ampliou a agenda política relacionada à Educação Infantil.

Em 1997, no Congresso Infantil Estadual de São Paulo, com o lema "Reforma Agrária, uma luta de todos e dos Sem Terrinha também", se assume a denominação de Sem Terrinha para as crianças (MST, 2017). No processo de expansão regional, os eventos destinados aos Sem Terrinha passaram a chamar-se "Encontros dos Sem Terrinha" ou "Jornada Sem Terrinha", geralmente realizado no mês de outubro como contraponto à perspectiva mercadológica conferida à celebração do "Dia da Criança" no Brasil. Na assunção de uma identidade política como Sem Terrinha, as crianças destacam (MST, 2017, p. 37-38):

[...] nós também temos que lutar para conquistar nossos direitos garantidos no Estatuto da Criança e do Adolescente. Hoje, nós, crianças e adolescentes, encontramos aqui o nosso espaço para manifestar nossos direitos através do canto, das brincadeiras, dos momentos artísticos e culturais, do estudo e da reflexão. O Congresso foi a nossa chance de propor nossas e novas ideias. [...] Nossa vida é uma vida de luta: aprendemos com os nossos pais que existe uma Lei de Reforma Agrária e para que ela seja cumprida tivemos que nos organizar, nos mobilizar para exigir o cumprimento de nossos direitos. [...] Portanto, por meio desse Manifesto, estamos dizendo à sociedade que nós, crianças dos acampamentos e assentamentos do MST/RS, estamos cientes dos nossos direitos e estamos lutando para que o Estatuto da Criança e do Adolescente seja cumprido na sua totalidade.

\footnotetext{
${ }^{10}$ Esta foi a primeira turma de Magistério da Terra formada pelo MST, em âmbito nacional, com a presença de 18 estados.
} 
Conforme o MST (2004), duas necessidades impulsionaram o processo de organização da Educação Infantil e do atendimento pedagógico das crianças: a primeira era o desafio de garantir a participação das mulheres no trabalho coletivo da produção, nas cooperativas e associações dos assentamentos. A segunda relacionava-se à garantia de maior participação das mulheres militantes do MST no conjunto das atividades políticas desenvolvidas pelo Movimento. Uma terceira questão era o desafio de aprofundar o estudo relacionado à Infância Sem Terra e a formação das educadoras e educadores infantis. Inicialmente, as discussões sobre a Educação Infantil no MST partiram (MST, 2017, p. 91):

[...] da necessidade de compartilhar com as famílias Sem Terra os cuidados e a educação de seus filhos e filhas, sendo coerentes com os ideais de justiça e transformação social que buscamos concretizar, combinando a luta pela garantia do direito à educação infantil com a intenção de construirmos coletivamente a formação de nossas famílias, das comunidades assentadas e acampadas que constituem o MST.

Com respeito à incorporação dos Sem Terrinha à organicidade, o MST assume-se como (MST, 2017, p. 91) "um grande educador das crianças Sem Terra, pois este é o meio no qual elas vivem suas infâncias, participando da luta pela terra, pela Reforma Agrária". Nessa direção, abre-se uma nova frente de trabalho destinada a ampliar a discussão sobre a educação familiar e sua interface com a formação das crianças Sem Terra. Nesta nova etapa do projeto educativo do MST, destacam-se como principais desafios (MST, 2004):

- A necessidade de que a comunidade, o coletivo e a escola infantil compartilhem com a família a educação das crianças de 0 a 6 anos;

- A ampliação da luta por políticas públicas para a Educação Infantil no Campo, incorporando a diversidade dos sujeitos que formam o campo; - A luta contra o trabalho infantil e o fomento da participação das crianças em atividades amenas no seio familiar e no aprendizado com o trabalho no campo; 
- A garantia dos direitos das crianças e o cumprimento do Estatuto da Criança e do Adolescente. ${ }^{11}$

Em 2007, o MST organiza o "Seminário Nacional: o lugar da Infância no MST", com o intuito de realizar um balanço no percurso teórico e educativo-pedagógico acerca da Infância Sem Terra. Na análise do MST, o histórico da Infância Sem Terra perpassa dois momentos (MST, 2017): o primeiro, ao situar o reposicionamento das crianças como sujeitos históricos no âmago da questão agrária e a luta pela terra, condição de ruptura com sua invisibilidade política. Tal processo conduziu a outras duas abordagens fundamentais na incorporação da infância Sem Terra: a compreensão de que no enfrentamento do latifúndio, a família Sem Terra se constitui como um sujeito de luta e uma luta que incorpora diferentes indivíduos, entre eles, as crianças. De igual maneira, como fruto da resistência dos corpos das mulheres Sem Terra, as crianças ocupam o corpo do MST, ao fazer-se presente nos diferentes espaços orgânicos e de ação política do Movimento.

O segundo momento do percurso histórico da Infância Sem Terra consistiu na incorporação das crianças em atividades mais amplas do MST, com destaque para: o $1^{\circ}$ Encontro Nacional de Educadoras e Educadores da Reforma Agrária (ENERA), em 1997, com a participação de 80 crianças; o IV Congresso Nacional do MST, em 2000, com a presença de 380 crianças e a realização da Marcha Nacional pela Reforma Agrária, em 2005, com a participação de 200 crianças.

Importante salientar que nesse processo de definição da Infância Sem Terra durante o "Seminário Nacional: o lugar da Infância no MST", o Estatuto da Criança e do Adolescente (ECA) é assumido como documento central para delimitar a concepção da infância, bem como no delineamento dos princípios que regem a dimensão dos direitos e das responsabilidades que devem ser assumidas com relação às crianças no âmbito da família, da sociedade e do Estado (MST, 2017).

${ }^{11}$ O Estatuto da Criança e do Adolescente é reconhecido, no âmbito do debate teórico e político do Setor de Educação, como documento de referência na definição da Infância e dos direitos a serem garantidos às crianças e adolescentes. 
Entretanto, também é fundamental destacar que esse Seminário apontou desafios centrais no debate da Infância Sem Terra, especialmente no aprofundamento teórico dos conceitos infância, criança, gênero, família e trabalho, considerados nodais no debate interno do MST com relação ao estudo e à definição da própria concepção de infância na perspectiva do movimento social. No Seminário também se debateu a necessidade de estabelecer ações e estratégias para politizar o tema da infância no âmbito do território e da organicidade do Movimento. Outra questão importante debatida no Seminário diz respeito à demanda de políticas públicas relacionadas aos direitos das crianças e, no plano educativo, para a formação das e dos educadores com ênfase na Educação Infantil (MST, 2017).

Com base no exposto, podemos inferir que a concepção da Infância Sem Terra e a Educação Infantil estão em construção e se incorporam profundamente ao debate teórico, pedagógico e político do Setor de Educação. Tornam-se um eixo de suma relevância no âmbito da luta pela Reforma Agrária, assim como as demais necessidades dos assentamentos, a exemplo da produção, da formação política da militância, entre outras. Conforme o MST (2011, p. 26):

O MST na sua filosofia defende e trabalha na perspectiva da construção de um outro ser humano, baseado em outros valores, para tanto, viemos fazendo o esforço de criar espaços coletivos, como os Encontros de Sem Terrinha, as Escolas Itinerantes, as Cirandas Infantis permanentes ou itinerantes para que as crianças, que em geral têm pouca voz, possam dialogar e reivindicar para o poder público e para o próprio Movimento o que querem para os assentamentos e acampamentos de Reforma Agrária, para que possam vivenciar experiências coletivas e dizer o que pensam do mundo.

É importante destacar o esforço do Setor de Educação no processo de elaboração teórica e de sistematização das experiências educativopedagógicas relacionados à Infância Sem Terra, que incorpora uma série 
de documentos produzidos internamente pelo Setor, em articulação com o Setor de Comunicação e Cultura, ademais de outras produções audiovisuais e do Jornal Sem Terrinha. Conforme Ramos (2013), os documentos produzidos pelo MST acerca da Infância Sem Terra podem ser divididos em três categorias: Documentos sobre a infância; Documentos para as crianças; Documentos para e com as crianças. ${ }^{12}$

Com a conquista da Política Nacional de Educação do Campo, o MST também avança no fortalecimento da formação educativa das educadoras e educadores infantis, sobretudo com a Licenciatura em Educação do Campo e Pedagogia da Terra. De igual maneira, as escolas do campo tem sido um espaço de articulação fundamental da Infância Sem Terra, ao impulsar campanhas, concursos literários, festivais, entre outras atividades que incorporam a participação das crianças Sem Terra.

No âmbito da Educação do Campo, o MST tem defendido o trabalho pedagógico e de formação política das crianças Sem Terra nas escolas do campo existentes nos assentamentos de Reforma Agrária, espaços nos quais se desenvolvem essas atividades e que visam, sobretudo, conformar uma identidade política das crianças com relação à identidade política do MST na defesa da terra e da Reforma Agrária Popular. Observamos essa construção identitária na produção literária e musical das Crianças Sem Terra, a exemplo da Coletânea de CD's Crianças em Movimento, de cordéis e poemas produzidos nas escolas do campo, entre outras expressões que visam fortalecer os valores humanistas, a identidade com o campo e como povo camponês, e o horizonte político do socialismo (MST, 1999). Também nas consignas políticas elaboradas pelas próprias crianças Sem Terra é possível ver a expressão desses valores, consignas que sempre se fazem presentes em suas atividades culturais e políticas, a propósito da "Campanha Fechar Escola é Crime", iniciada pelo MST em 2011.

O Setor de Educação, por sua vez, também tem encabeçado atividades nacionais, como concursos de redação e desenho elaborados pelos Sem Terrina. Entre aqueles que se destacam:

\footnotetext{
${ }^{12}$ Para aprofundar a abordagem da Infância Sem Terra nos documentos e demais materiais produzidos pelo MST sugerimos o estudo desenvolvido por Ramos (2013; 2016).
} 
- Movimento Sem Terra: por escola, terra e dignidade (1997);

- Desenhando o Brasil: o Brasil que queremos (1999);

- MST, quantos anos você tem? Terra e Vida (2003);

- As sementes são patrimônio da humanidade (2005);

- Fechar escola é crime (2012).

Além dos desdobramentos de ordem teórica e política, resultantes desse processo de aprofundamento nos espaços de estudo e de organização política do MST, o debate da Infância Sem Terra abriu caminho para uma experiência educativo-pedagógica genuína, com a criação das chamadas Cirandas Infantis, conforme abordaremos a seguir.

\section{AS CIRANDAS INFANTIS E A SUBJETIVIDADE POLÍTICA DA INFÂNCIA SEM TERRA}

Uma das primeiras experiências de acompanhamento pedagógico das crianças em contextos de assentamentos da Reforma Agrária aconteceu em 1990, na Cooperativa de Produção Agrícola - COOPAUL, no Município de Hulha Negra - RS. A criação da cooperativa implicava a organização coletiva dos assentados para a realização dos trabalhos de produção. A inserção das mulheres na cooperativa estava diretamente vinculada à necessidade de incremento da renda familiar. Entretanto, para que elas participassem ativamente na atividade produtiva era fundamental garantir o atendimento das crianças. A criação da creche foi uma resposta imediata à demanda das mulheres assentadas (BIHAIN, 2001). Esta primeira iniciativa constituiu um marco no processo de inclusão das mulheres assentadas nos processos produtivos dos assentamentos, bem como na luta por creches paras as crianças assentadas. Posteriormente, outras Cooperativas de Produção Agrícola (CPAs) implantaram creches e, em alguns assentamentos, conquistou-se a pré-escola.

Paulatinamente, a Frente de Educação Infantil Nacional avançou na perspectiva pedagógica das creches que, à inspiração da experiência cubana dos Círculos Infantis, passaram a denominar-se "Círculos Infantis" (MST, 2017). Outra tarefa da Frente de Educação Infantil Nacional era a de pensar um nome que pudesse expressar a dimensão da Educação Infantil 
para as crianças Sem Terrinha e em consonância com a luta política do MST. Assim, foi realizada uma consulta nacional aos estados para a escolha de um nome para a Educação Infantil. Entre as várias sugestões, o nome "Ciranda" foi o mais votado no Coletivo Nacional. O nome Ciranda alude a crianças em movimento. Conforme o MST (2017, p. 91):

[...] a partir de um longo processo de discussão nos coletivos de educação estaduais e nacional, passamos a chamar nossos espaços de educação infantil de ciranda infantil, nome que se refere à nossa cultura popular, às nossas danças, às brincadeiras, e à cooperação, à força simbólica do círculo coletivo e ao ser criança.

O nome Ciranda Infantil foi proposto pelo Setor de Educação do MST-Ceará. Em conformidade com a discussão realizada em âmbito nacional, Maria de Jesus dos Santos ${ }^{13}$ - considerada a idealizadora das Cirandas Infantis - argumenta que a proposta da Educação Infantil nasce de duas experiências: primeiro, da demanda das mulheres que participavam de várias frentes de resistência, como por exemplo, as que faziam parte do Sindicato dos Profissionais da Educação, no interior do Ceará. Ao nos relatar essa experiência, Maria de Jesus recupera a memória de sua participação nesse processo, anterior à sua inserção como militante no MST. Nesse período, participou ativamente no movimento sindical, cuja principal bandeira de luta era a construção de creches nos locais de trabalho.

A segunda experiência adveio da necessidade de participação das mães militantes nos diversos espaços de formação política organizados pelo MST. Maria de Jesus observou que algumas mulheres se afastavam do Movimento por não terem um espaço educativo dedicado aos seus filhos (as) e que lhes permitisse participar das várias atividades desenvolvidas pelo MST. Tal demanda foi discutida pelo Setor de Educação do Ceará,

\footnotetext{
${ }^{13}$ Em entrevista realizada durante a realização de nossa pesquisa de campo. Maria de Jesus dos Santos é militante do MST-Ce desde o ano 1992. É considerada a fundadora da proposta educativo-pedagógica das Cirandas Infantis.
} 
conjuntamente com Maria de Jesus que já propunha a proposta da Ciranda Infantil como uma alternativa à formação educativa das crianças e para viabilizar a participação política e produtiva das assentadas.

$\mathrm{Na}$ verdade, Maria de Jesus tinha um sonho. Em suas palavras, "a questão do sonho é sempre presente; todo educador é movido por sonhos" $"$. No ano de 1995, Maria de Jesus deu a luz à sua primeira filha. Por tal razão, voltar a atuar na militância era um grande desafio, uma vez que teria que conciliar a maternidade com as responsabilidades e atividades no Movimento. O fato de não ter um espaço educativo para deixar os filhos dificultava uma maior participação. Em relato diz:

Eu tinha um sonho: primeiro eu sonhava que nós criássemos (não pensando só em mim, mas nas mulheres) um ônibus que fosse uma creche itinerante, com tudo que tivesse direito para as crianças, que onde nós fossemos nos reunir, onde nós fossemos organizar um acampamento, a gente levava o ônibus.

É válido salientar que outro aspecto fundamental para o surgimento da Ciranda Infantil era a necessidade de garantir um espaço que atendesse às demandas de formação educativo-pedagógica da criança na primeira infância. Um espaço no qual as crianças pudessem realizar atividades de crianças, como crianças e, assim, gradativamente deixar de ocupar os mesmos espaços dos adultos. Isso porque, a ausência de um espaço específico para que as crianças manifestassem suas necessidades, seus interesses e seus sentimentos, desembocava em uma situação de incômodo, em que estas crianças terminavam sendo consideradas inoportunas. Ademais, a presença da Ciranda Infantil evitava situações de desconforto e advertência para as mães durante a realização de algum curso ou nas demais atividades realizadas pelo MST.

Assim nasce a Ciranda Infantil no MST, um espaço educativo próprio para a criança de zero a seis anos de idade (embora também atenda crianças de até 10 anos de idade). As Cirandas Infantis constituem

${ }^{14}$ Em entrevista realizada durante pesquisa de campo. 
um local de educação não formal e são mantidas pelas Cooperativas, Centros de Formação e pelo próprio Movimento. São espaços que buscam consolidar uma formação educativa, desde uma perspectiva lúdica e de vínculo orgânico com a luta do MST.

A abordagem pedagógica da Ciranda Infantil contempla a ludicidade própria das crianças Sem Terrinha, reconhecendo-as como protagonistas de seu processo educativo. São organizadas com base na Pedagogia do Movimento, com o intuito de igualmente formar ao sujeito históricopolítico Sem Terrinha e, por conseguinte, fortalecer a organicidade do MST. Para tanto, nas atividades pedagógicas, as crianças são instigadas a desenvolver a cooperação; viabilizar uma interação das mesmas com outros setores do MST, ao mesmo tempo em que constrói sua própria reflexão, como crianças, em torno dos seus direitos e de seu papel político na luta pela terra, pela educação, por reforma agrária (SALES e BARBOSA, 2016).

Por outro lado, conforme mencionado, há a preocupação em garantir a formação das educadoras e educadores infantis, além de promover junto aos assentamentos e acampamentos atividades que aportem ao desenvolvimento da Educação Infantil, como por exemplo, a produção de materiais didáticos, palestras, seminários, oficinas, entre outras atividades, como prática formativa do coletivo com relação à Infância Sem Terra e seu vínculo orgânico com o MST (MST, 2004).

Há duas experiências de Ciranda Infantil no MST, quais sejam: a Ciranda Infantil Permanente, que acontece quando está organizada dentro de um assentamento ou acampamento, em uma Cooperativa de Produção, nas escolas de formação educativo-política do MST, entre outros espaços físicos do Movimento. O critério da Ciranda Infantil Permanente consiste em que o processo seja organizado com um público infantil mais fixo, com periodicidade e em encontros mais frequentes.

A segunda experiência é a Ciranda Infantil Itinerante, que acontece em diferentes espaços de atuação política do MST, como as ocupações, cursos, reuniões, congressos, marchas, enfim, no movimento dialético da luta pela terra. Seu caráter itinerante expressa sua forma de organização em movimento, o que assegura a presença das famílias, das crianças e das 
educadoras e educadores infantis nos diferentes espaços de atuação política do MST, cumprindo com os postulados da formação educativa e política mediada pela Pedagogia do Movimento. Ambas as experiências de Cirandas Infantis são constituídas por um espaço educativo da vivência de ser criança Sem Terrinha, que lhes permite desenvolver sua ludicidade e cultivar a mística da resistência, tendo como embasamento teórico e político os valores e princípios organizativos e formativos do MST (BARBOSA, 2015b).

A proposta pedagógica vivenciada nas Cirandas Infantis do MST é um construto cotidiano e de caráter interdisciplinar. Vale ressaltar, que o Movimento tem incluído em sua prática pedagógica o caráter lúdico da aprendizagem. Nesse espaço educativo, as crianças Sem Terrinha constroem as relações entre si, com os adultos e com o mundo, aprendem a dividir o lápis, o brinquedo, a merenda, constroem suas identidades de Sem Terra; também inventam, criam e recriam sua relação consigo mesmas e com a bandeira política do MST. Ademais, o grande diferencial da Ciranda Infantil é que além de ser um espaço de brincadeiras, de encontro entre as crianças, desenvolve também uma prática pedagógica voltada à formação de um sujeito histórico-político Sem Terrinha, o que lhe confere um caráter de educação emancipadora. Por exemplo, quando há atividades políticas e de formação do MST, sempre é definido na programação um momento para que as Crianças Sem Terra apresentem aos adultos as atividades que estão a desenvolver na Ciranda Infantil.

A Ciranda Infantil também é um espaço que garante os cuidados básicos das crianças e de seu processo educativo. Com respeito a este aspecto, é fundamental a formação das educadoras e educadores infantis. Inicialmente, o perfil das educadoras e educadores do MST não contemplava uma formação específica no campo da Educação Infantil, dado que normalmente quem assumia essas atividades eram as mães, pais, uma jovem, um jovem, com baixa escolarização e conhecimentos sobre a infância e sobre a criança dessa faixa etária.

Entretanto, havia a consciência de que o trabalho pedagógico com crianças requer de muita atenção e acompanhamento, além de uma formação adequada no campo educativo-pedagógico relacionado à 
Educação Infantil. Sendo assim, o Setor de Educação definiu dois eixos básicos indispensáveis à formação desses educadores infantis: a construção de um vínculo afetivo com a criança e o desenvolvimento das habilidades básicas para seu cuidado, seu atendimento e sua educação.

Com base nessa reflexão, o MST organizou a Primeira Oficina de Educadoras e Educadores Infantis, em 1996, com o objetivo de discutir o conceito de infáncia e as diferentes fases de seu desenvolvimento, como a fala, os processos de sociabilidade das crianças, seus direitos, seus espaços lúdicos, entre outros aspectos relacionados à psicologia da infância. A segunda oficina aconteceu em 2007 e tinha por finalidade contribuir com elementos teórico-pedagógicos relacionados à formação educativa na infância, em articulação com o processo de organização das Cirandas Infantis na base do Movimento, ademais de aprofundar o debate acerca da função educativa e política das Cirandas Infantis para o MST.

Concretamente, a primeira experiência de Ciranda Infantil Itinerante aconteceu no Ceará, em outubro de 1996, com o nome "Ciranda Infantil Paloma" (em homenagem a uma criança que tinha morrido em um dos assentamentos $)^{15}$. Em sua constituição teve apoio do $\mathrm{UNICEF}^{16}$ e sua intencionalidade educativo-pedagógica consistia em ofertar atendimento ao grande número de crianças presentes nos encontros de formação dos adultos do MST. De igual maneira, buscava consolidar processos educativos, organizados em uma rotina diária, tempos e espaços destinados à formação educativo-política das crianças Sem Terrinha que acompanhavam suas mães.

Neste sentido, a Coordenação Estadual do MST-Ceará, conjuntamente com as educadoras e as mães, elaboraram um documento para definir as responsabilidades e atribuições de todos os sujeitos envolvidos na Ciranda Infantil, com o intuito de garantir uma adequada dimensão pedagógica às atividades desenvolvidas com as crianças nos diferentes espaços formativos do Movimento.

\footnotetext{
${ }^{15}$ Conforme registro em diário de campo em diálogo informal realizado com Maria de Jesus Gomes.

${ }^{16}$ UNICEF - Fundo das Nações Unidas para a Infância. Desenvolve no MST um programa voltado para o atendimento das necessidades básicas da criança e do adolescente.
} 
Em âmbito nacional, a primeira Ciranda Infantil Itinerante Nacional aconteceu no marco do Encontro Nacional das Educadoras e Educadores da Reforma Agrária - ENERA, entre os dias 28 a 31 de julho de 1997, no campus da Universidade de Brasília - UnB, com a participação de 80 crianças de todo o país. Muitos foram os desafios encontrados nessa primeira experiência de Ciranda Infantil Nacional: a organização de um espaço que permitisse o pleno desenvolvimento das atividades pedagógicas com as crianças; formar as educadoras e educadores infantis (a maioria não tinha experiência com o trabalho pedagógico com crianças, apresentavam dificuldade para desenvolver brincadeiras, as cantigas de roda, etc.). Outro desafio era o fato da maioria das educadoras e educadores infantis não utilizarem o planejamento feito pela Coordenação Nacional do Setor de Educação. Neste sentido, a partir dessa primeira experiência nacional ficou decidido que para as próximas Cirandas Infantis, o planejamento deveria ser feito conjuntamente com as educadoras e educadores infantis.

Paulatinamente foram sendo incorporadas outras experiências de Ciranda Infantil Itinerante. Assim, no ano de 2000, o Setor de Educação organizou uma Ciranda Infantil Itinerante durante o IV Congresso Nacional do MST, com a presença de 320 crianças filhas(os) de militantes que participavam como delegados(as) vindos(as) de 23 estados do Brasil. Esta Ciranda tornou-se uma referência para a organização das próximas Cirandas Infantis, uma vez que se alcançou a intencionalidade pedagógica com as atividades desenvolvidas com as crianças, oportunizando a troca de saberes e de experiências entre as mesmas.

Em 2007, no V Congresso Nacional do MST ${ }^{17}$, foi organizada a Ciranda Infantil Paulo Freire, com a presença de 1000 crianças (de 0 a 10 anos de idade) e 400 educadores e educadoras infantis. Para a realização desta Ciranda Infantil, o MST realizou uma formação para os coordenadores estaduais da ciranda, que aconteceu na Escola Nacional Florestan Fernandes, entre os dias 12 a 16 de maio de 2007. O principal objetivo era que esta formação fosse reproduzida nos demais estados,

${ }^{17} \mathrm{O}$ V Congresso do MST aconteceu nos dias 11 a 15 de julho, em Brasília, com 15 mil delegadas e delegados vindos de todos os assentamentos e acampamentos do MST em todo o Brasil. 
garantindo a formação prévia das educadoras e educadores infantis, sobretudo daqueles que participariam do V Congresso Nacional.

No VI Congresso Nacional do MST, a Ciranda Infantil Paulo Freire contou com a participação de aproximadamente 1.000 crianças Sem Terrinha e 150 educadoras e educadores infantis. Conforme Elisângela Carvalho $^{18}$, coordenadora da Ciranda Infantil Paulo Freire, o processo de organização da ciranda ocorre cinco meses antes do Congresso Nacional e em dois níveis, a saber: a oficina nacional, com o objetivo de construção do planejamento educativo-pedagógico para os cinco dias de Congresso. O segundo momento é a formação de cada educadora e educador infantil em seu próprio estado.

Ao acompanharem seus pais na luta pela terra e pelo direito à educação, os Sem Terrinha tornam-se sujeitos construtores de um processo transformador, alicerçado em ideais, em uma visão prospectiva de galgar os caminhos para a transformação de sua própria realidade, tendo como referência os princípios políticos da organicidade e coletividade. Portanto, a inserção ativa das crianças nas lutas, sobretudo, na luta pela terra, por escola e dignidade propicia a formação de uma consciência crítica desde os primeiros passos da formação humana, isto é, durante a própria infância. Esse é um processo construído nos espaços de atuação política do MST, como também nos acampamentos e assentamentos, nas atividades cotidianas realizadas nas escolas do campo e nas Escolas Itinerantes, na busca permanente por assegurar que as atividades formativas da escola contemplem a dimensão política e identitária da luta do MST.

Conforme mencionado no artigo, o MST se considera como o grande educador das crianças Sem Terrinha (MST, 2017). É em meio ao cotidiano da resistência no campo, no confronto direto do latifúndio da terra e do modelo econômico preconizado pelo capital que as crianças Sem Terrinha constroem sua identidade política e o conjunto de aprendizagens que associam seus conhecimentos à luta pela Reforma Agrária.

\footnotetext{
${ }^{18}$ Em http:/ /www.resumenlatinoamericano.org/?p=2215
} 


\section{DOS AVANÇOS, DESAFIOS E BANDEIRAS DE LUTA DA INFÂNCIA SEM TERRA: REFLEXÕES FINAIS}

$\mathrm{Na}$ dialética da luta pela emancipação camponesa latino-americana cobra vitalidade o papel político desempenhado pelas crianças Sem Terrinha. Isto porque na história da resistência nacional e internacional, sempre foram os adultos, especialmente os homens, aqueles que figuram (ou são reconhecidos) como sujeitos impulsionadores de processos políticos. Portanto, é fundamental dar visibilidade à participação direta das crianças em movimentos sociais e organizações populares, no sentido de articulação de um projeto político próprio, tecido organicamente com um coletivo em movimento.

O MST se desafiou a construir sua compreensão em torno da Infância Sem Terra, ao reconhecer a presença em movimento das crianças Sem Terrinha, inclusive reconhecendo-as como cultura nos diferentes espaços de luta e formação política do Movimento (MST, 2017). Nessa trajetória, o MST se sentiu instigado a pensar a inclusão política dos pequenos na luta pela terra e pela reforma agrária. E mais: a debater o próprio conceito de infância em contextos rurais, em perspectiva histórica e política. Nessa direção, é possível afirmar a existência de uma concepção da Infância Sem Terra, conceito em construção e em estreita relação com a valorização da criança e da infância na perspectiva da luta camponesa e da realização da Reforma Agrária.

Em um momento em que se consolida um golpe político no Brasil não são poucos os desafios postos no campo popular e, sobretudo, para os movimentos sociais do campo, sobretudo com relação aos cortes orçamentários e as descontinuidades do PRONERA, ao incremento do fechamento das escolas do campo e à ofensiva do agronegócio nos territórios e na disputa educativo-pedagógica das escolas (LAMOSA, 2016; PERICÁS, 2017; BARBOSA, 2017; 2018,). Para o caso específico dos Sem Terrinha, tais desafios são incorporados a sua agenda política como crianças. Sendo assim, uma das principais bandeiras de luta dos Sem Terrinha está relacionada diretamente com a reivindicação do direito à educação: dar continuidade à Campanha Fechar Escola é Crime, ao 
mesmo tempo em que se reivindica a implementação de Políticas Públicas Educativas específicas para a Infância no e do campo, seja na ampliação das escolas do campo em áreas de assentamentos da Reforma Agrária, como também para a formação das educadoras e educadores infantis.

Em 2018, o Setor de Educação realiza o I Encontro Nacional dos Sem Terrinha. Um diferencial desse encontro consiste na participação direta de 30 crianças e adolescentes na oficina preparatória, realizada em setembro de 2017. Conforme Márcia Ramos, do Setor de Educação: ${ }^{19}$

Pra nós, é importante que as crianças, desde pequenas, convivam com esse processo organizativo, que sejam organizadas, que aprendam desde pequenas - principalmente nesta conjuntura agora, de 'Escola sem Partido', de golpe - a serem críticas, a não aceitarem as imposições que são colocadas pra elas.

Portanto, no I Encontro Nacional dos Sem Terrinha há a intenção de debater os impactos da "Escola sem Partido" no processo educativo corrente nas escolas, sobretudo no retrocesso de uma perspectiva educativa emancipadora. Almeja-se, também, evidenciar a problemática histórica do acesso à educação nos contextos rurais, que se reflete no fechamento de 24 mil escolas em todo o país.

De igual maneira, o Encontro visa fortalecer a agenda política dos Sem Terrinha com relação à alimentação saudável na perspectiva da Educação do Campo e da agroecologia, projeto político que se contrapõe ao agronegócio e seus impactos ambientais, sociais e econômicos para os povos do campo.

No que concerne ao avanço na compreensão da Infância Sem Terra e do processo educativo dos Sem Terrinha, o MST tem por diante o enorme desafio de avançar na concepção da Infância Sem Terra na perspectiva do Movimento e, em particular, para construir estratégias políticas que permitam avançar na formação das educadoras e educadores infantis. A

19 MST lança $1^{\circ}$ Encontro Nacional dos Sem Terrinha. Disponível em: https://www. brasildefato.com.br/2017/09/07/mst-lanca-1o-encontro-nacional-dos-sem-terrinha/

Temáticas, Campinas, 26, (51): 119-148, fev./jun. 2018 
aprovação da PEC 55 e da MP 746/2016 impactaram na redução de um dos principais Programas conquistados pelo MST, a saber, o Programa Nacional de Educação na Reforma Agrária (PRONERA): em 2016, os recursos chegavam a $\mathrm{R} \$ 30$ milhões e, em 2017, caíram para 11,8 milhões. A previsão é de que em 2018 se reduza ainda mais o montante, com a liberação de apenas R 33 milhões para o Programa. Tal redução prejudica o processo de formação permanente dos educadores vinculados ao MST, ao mesmo tempo em que cria os mecanismos legais para anular ou frear processos educativos de caráter emancipatório.

Entretanto, se pensarmos a dimensão formativa do próprio MST, vemos que outro desafio permanente consiste em manter viva a Pedagogia do Movimento na perspectiva da Infância Sem Terra, por meio de uma pedagogia voltada para a realidade das crianças do campo, que fortaleça sua identidade Sem Terra, haja vista que, ao estudar numa escola convencional, os (as) filhos (as) dos (as) trabalhadores (as) rurais acabam expostos à iminente perda da identidade camponesa.

Um grande desafio à Escola Itinerante e à Ciranda Infantil é a falta de políticas públicas para a Educação Infantil do e no Campo. Desta forma, cabe aqui uma reflexão: embora o Estado seja um sujeito que deve garantir institucionalmente os direitos, na prática não garante a emancipação. Neste sentido, limitar a Educação Infantil do e no campo apenas ao âmbito dos direitos, é descartar os esforços do MST no que concerne a emancipação como princípio e projeto político. Vendo por esse ângulo, a autonomia na organização do trabalho pedagógico nas Escolas Itinerantes e nas Cirandas Infantis tende a limitar-se à perspectiva institucional dos direitos e ainda será longo o caminho para que se alcance uma educação emancipatória.

Assim, fica evidenciada a grande bandeira de luta pela educação infantil por parte do MST. Sem dúvida é indispensável travar essa luta pela garantia dos direitos das crianças, porém, essa luta também deve garantir o direito à educação para a ação da transformação defendida pelo MST. 


\section{REFERÊNCIAS BIBLIOGRÁFICAS}

BARBOSA, Lia Pinheiro. Dilemas de los movimientos sociales campesinos frente a las disyuntivas entre los gobiernos progresistas y el ascenso de las nuevas derechas en América Latina: el caso de Brasil. Conference Paper $\mathrm{n}^{\circ}$ 26. ERPI 2018 - International Conference "Authoritarian Populism and the Rural World". Institute Social Studies, The Hague, 2018. Disponível em: <https://www.iss.nl/en/authoritarian-populismand-rural-world $>$.

- Movimentos Sociais e Políticas Públicas no contexto das reformas em curso no Brasil. O Público e o Privado, $\mathrm{n}^{\circ} 30$, jul-dez, p.129-153, 2017.

. Educação do Campo [Education for and by the countryside] as a political project in the context of the struggle for land in Brazil. The Journal of Peasant Studies, 40, p. 118-143, 2016.

- Educação do Campo, movimentos sociais e a luta pela democratização da Educação Superior: os desafios das universidades públicas no Brasil. In: SILVA, Adrián. Acosta et. al. Los desafíos de la universidad pública en América Latina y el Caribe. Buenos Aires: CLACSO, p. 147-212, 2015a.

- Educación, resistencia y movimientos sociales: la praxis educativopolitica de los Sin Tierray de los Zapatistas. México: LIBRUNAM, 2015b.

. Por la democratización de la Educación Superior en Brasil: el PRONERA en el arco de la lucha de los movimientos campesinos. Universidades, núm. 56, abril-junio, p. 20-31, 2013a.

. Educación, Movimientos Sociales y Estado en América Latina: estudio analítico de las experiencias de resistencia contrabegemónica en Brasily México. Cidade do México, 2013b (Doutorado em Estudios Latinoamericanos). Programa de Posgrado en Estudios Latinoamericanos, Universidad Nacional Autónoma de México. 
BIHAIN, Neiva Marisa. A trajetória da educação infantil no MST: de Ciranda em ciranda aprendendo a cirandar. Porto Alegre, 2001. (Mestrado em Educação). Faculdade de Educação, Universidade Federal do Rio Grande do Sul.

CALDART, Roseli. Salete. Pedagogia do Movimento Sem Terra. São Paulo: Expressão Popular, 2004.

DERMEVAL, Saviani. Escola e democracia. São Paulo: Cortez / Autores Associados, 1983.

LAMOSA, Rodrigo de Azevedo Cruz. Educação e Agronegócio: a nova ofensiva do capital nas escolas públicas. Curitiba: Appris, 2016.

MST. Educação no MST - Memória. Documentos 1987-2015. Caderno de Educação, no 14, junho. São Paulo: Setor de Educação, junho de 2017. - Educação da Infância Sem Terra. Orientações para o trabalho de base. Caderno da Infância, n. 1. São Paulo: Setores de Educação, Gênero e Cultura, 2011.

. Cadernos da Escola Itinerante - MST. Ano VIII, no 1. Curitiba: Setor de Educação do MST, abril de 2008a.

. MST, Itinerante: a Escola dos Sem Terra - Trajetórias e Significados. Cadernos da Educação Itinerante, no 2. Curitiba: Setor de Educação, outubro de 2008b.

. Dossiê MST e Escola. Documentos e estudos - 1990-2001. Caderno de Educação, no 13. São Paulo: Expressão Popular, 2005.

. Educação Infantil: Movimento da vida, Dança do Aprender. Caderno de Educação, nº ${ }^{\circ}$ 12. São Paulo: Setor de Educação, novembro de 2004.

- Construindo o caminho numa escola de assentamento do MST. Faz̧endo escola. Porto Alegre: Setor de Educação, 2000. . Como fazemos a Escola de Educação Fundamental. Caderno de Educação, número 09. Rio Grande do Sul: Setor de Educação, 1999. 
Escola Itinerante: uma prática pedagógica em acampamentos.

Fazendo a Escola. Porto Alegre: Setor de Educação, 1998.

PERICÁS, Luiz Bernardo. Monopólios, desnacionalização e violência: a questão agrária no Brasil hoje. Margem Esquerda, 29, p. 59-71, 2017, 29.

RAMOS, Márcia Mara. Educação, trabalho e infância: contradições, limites e possibilidades no Movimento dos Trabalhadores Rurais Sem Terra. Campinas, 2016. (Mestrado em Educação). Programa de Pós-Graduação em Educação, Universidade Estadual de Campinas.

A significação da infância em documentos do MST. Rio de Janeiro, Revista Tamoios, no 02, jul-dez, p. 73-95, 2013.

SALES, Mirna Soares; BARBOSA, Lia Pinheiro. A Educação Infantil no MST: um olhar sobre a Ciranda Infantil no Assentamento Palmares - Ceará. In: MOREIRA, Érika Macedo; LIMA, Mariana Cruz de Almeida. Cadernos da Educação do Campo. Série Cadernos do Residência Agrária 02. Brasília: PRONERA, 2016.

STÉDILE, João Pedro. (org.). A Reforma Agrária e a luta do MST. Petrópolis: Vozes, 1997.

Texto recebido em 12/12/2017 e aprovado em 13/04/2018. 